\title{
Industrial park land capability assessment and post-evaluation in Markazi province
}

\author{
Amir Hedayati Aghmashhadi ${ }^{1,2} \cdot$ Ali Azizi $^{3} \cdot$ Maryam Hoseinkhani ${ }^{2} \cdot$ Samaneh Zahedi ${ }^{4} \cdot$ Giuseppe T. Cirella $^{5}$ (D)
}

Received: 21 May 2021 / Accepted: 7 December 2021 / Published online: 21 December 2021

(c) The Author(s) 2021, corrected publication 2022

\begin{abstract}
Markazi province in Central Iran is a highly attractive area for the development of industrial centers; however, over the last few decades, unregulated development has led to environmental and socioeconomic issues. The purpose of this research is to evaluate the existing industrial parks and identify potential areas for appropriate development. An industrial land capability assessment utilized 14 main criteria and 10 constraint parameters of socioeconomic, infrastructural, biological, and physical aspects using a geographic information system-based analytical network process model. Results show that Markazi province has $14.27 \%$ of highly suitable and $11.32 \%$ of extremely suitable area for industrial development; contrariwise, $60.14 \%$ of the province has no potential or is classified as an exclusion zone. Moreover, $44.4 \%$ (i.e., 8 parks) of the province's industrial parks are located in unsuitable zones. According to the land capability of Markazi province, the need to organize existing industrial parks and integrate industrial units alongside existing centers and potential areas should be considered in the industrial development policies of the province. The results of the sensitivity analysis also support the research findings.
\end{abstract}

Keywords Industrial development $\cdot$ MCDM $\cdot$ GIS $\cdot$ Semi-arid area $\cdot$ Iran

\section{Introduction}

Sustainability involves the sustained use of natural resources as well as an understanding of the impact on the environment due to pollution, waste, and land use (Zhang et al., 2019). In the past, site selection was based almost purely on economic and technical criteria. Today, a higher degree of sophistication is expected. Selection criteria must also satisfy a number of

Giuseppe T. Cirella

gt.cirella@ug.edu.pl

Amir Hedayati Aghmashhadi

a-hedayati@araku.ac.ir

Ali Azizi

aliazizi89@psri.ac.ir

Maryam Hoseinkhani

mrm.hkhani72@gmail.com

Samaneh Zahedi

smnhzahedi@yahoo.com

1 Department of Sustainable Landscape Development, Institute of Geosciences and Geography, Martin Luther University Halle-Wittenberg, German Centre for Integrative Biodiversity Research (iDiv) Halle-Jena-Leipzig,

06120 Halle, Germany environmental and social requirements, which are enforced by legislation and government regulation (Khamis et al., 2020). In this sense, it is possible to consider the evaluation of alternative projects like a complex decision problem where different aspects need to be considered simultaneously, taking into account both technical elements which are based on empirical observations, and non-technical elements which are based on social vision, preference, and feeling (Munda, 2004; Mondini,

2 Department of Environmental Science and Engineering, Faculty of Agriculture and Environment, Arak University, Arak, Iran

3 National Population Studies and Comprehensive Management Institute, Tehran, Iran

4 Department of Environmental Management, Islamic Azad University, Tehran Science and Research Branch, Tehran, Iran

5 Faculty of Economics, University of Gdansk, 81-824 Sopot, Poland 
2016). The process selection of site means complex multi-criteria analysis which includes a complex array of factors involving environmental, social, economic, technical, and political issues that may result in conflicting objectives (Rikalovic et al., 2014). The design and implementation of geographic information system (GIS)-based models can resolve the problems (Malczewski, 2004, Diaz and Soares, 2020) associated with industrial area demands. As a result of this, the negative impacts will be minimized and the sustainability and profitability of industry maximized. Selecting the proper location of facilities plays an important role in lowering distribution costs, reducing freight traffic movements, and minimizing the impact on the environment and residents (Izadikhah and Saen, 2016). Various multi-criteria decision-making (MCDM) methods have been applied in selecting the location of logistics facilities. Analytic network process (ANP) method, an MCDM ranking approach, is a viable technique to evaluate alternative locations based on key decision criteria to minimize distribution costs and negative impacts (Arsic et al., 2017; Seyedmohammadi et al., 2019; Caner and Aydin, 2021). As an MCDM problem, the common solution is based on the utility theory, such as simple linearity weighted method, ANP, and technique for order preference by similarity to an ideal solution (Chao et al., 2020). These improvements have allowed users to develop new models for identifying the best locations for industrial areas. The use of a hybrid GIS-criteria model using quantitative representation of each criterion as well as reducing uncertainties and facilitating the use of decision support systems can aid in determining a location's suitability (Hasala et al., 2020). The application of the model is demonstrated as a case study of the Markazi Province in the central part of Iran.

Industry growth is a phenomenon that has recently been considered with regard to utilizing the capabilities of each region (Salari et al., 2019). One of the key factors in regional development planning is finding a suitable place for the establishment of industrial zones (Arabsheibani et al., 2016). Industrial areas locating is a process which indicates the best place for running a project with respect to socioeconomic and environmental conditions (Reisi et al., 2011). Growing industrial and economic activities along with population growth can neglect the optimum usage of natural resources and disturb the balance of the environment (Al-Mulali et al., 2015). An industrial park is a set of industries placed together to share common services (Fernández and Ruiz, 2009). In many countries, industrial areas play an important role in economic strategy, and promotion and planning of these areas are substantial parts of urban planning (Arabsheibani et al., 2016). To meet the needs of sustainable development, many cities around the world have implemented the relocation of urbanindustrial enterprises (Cao et al., 2020). Years of production in the form of pollutants have caused serious issues, which pose high environmental and health risks. These polluted areas urgently need to be effectively managed and repaired to achieve redevelopment and utilization of the land. Dealing with large-scale redevelopments can comprise of a complex and dynamic system, characterized by contrasting stakes and urban concerns, effectively changing the decision-making process. Such systems increase in complexity in the case of preindustrial area developments since several additional concerns are necessary (Rikalovic et al 2014). One of the main problems of best industrial site selection is the lengthy period of time, i.e., from the sizeable amount of data, required for quality analysis. To speed up the decision-making process, it is necessary to develop a model optimized and adapted for industrial site selection (Rikalovic et al., 2017). Site selection is one of the basic vital decisions in the start process, expansion, or relocation of businesses of all kinds. One of the main objectives in industrial site selection is finding the most appropriate site with desired conditions defined by the selection criteria (Rikalovic et al., 2014). It is a complex process that should consider multiple alternative solutions and evaluation criteria (Li et al., 2017). By using mathematical analysis methods, including GIS (Izadikhah and Saen, 2016) and multi-criteria analysis (Chauhan and Singh, 2016), decision-makers can solve the problem of site selection and, ultimately, achieve the most suitable industry-specific site ( $\mathrm{Li}$ et al., 2017; Aljohani and Thompson, 2020).

Spatial design software such as GIS is commonly used for spatial planning of industry areas. Different sets of feasible and local-oriented evaluation criteria are designed for identifying optimum alternative locations in order to improve industry site situations. Recently, there have been a lot of studies reporting on the application of ANP to variety of problems in industrial park location selection through the GIS-ANP method (Giap et al., 2005; Rikalovic et al, 2014; Khavarian-Garmsir and Rezaei, 2015; Izadikhah and Saen, 2016; Rikalovic et al 2017; Diaz and Soares, 2020). The need to generate territorial information reinforces the importance of using spatial analysis combined with MCDM techniques (Meaden and AguilarManjarrez, 2013; Ross et al., 2013). GIS is a digital database management system designed to manage large volumes of spatially distributed data collected from a variety of sources. It is ideal for site selection studies because it efficiently stores, retrieves, analyzes, and displays information according to userdefined specifications (Hadipour et al., 2014). Markazi province, due to its suitable infrastructure and exceptional position in Iran, has always been considered by investors and the government prime real estate for the establishment of industries and industrial units. The unregulated development of industries and population growth issues over the last few decades have created a number of problems for indigenous communities and decision-makers alike. Hence, long-term planning regarding the future development of industries in the province requires understanding the current situation as well as the qualitative division in the province in terms of land capability evaluation. To rectify the aforementioned problem in Markazi province 
and develop appropriate policy-making, a correct and comprehensive study of the province is needed for the establishment of future industrial sites, while still controlling the current situation of industrial parks in terms of their management. To achieve this goal, specific innovative use of all existing and related layers is evaluated in terms of the industrial land of Markazi province. In addition, with the network comparison in the form of the ANP model, both weighting between the main criteria and sub-criteria will be done to achieve more desirable results. Considering human and natural constraints alongside the main layers will aid in improving the quality of the study. At length, it should be noted that using the raster base approach will also help improve the quality of research by valuing each pixel. A breakdown of the paper is structured as follows: the "Materials and methods" section contains the methodology used to formulate the mapped results, the "Results" section illustrates the findings, the "Discussion" section elucidates a discussion on developing the applicability of the research, and the "Conclusion" section concludes with a look at improving the study for future development.

\section{Materials and methods}

\section{Study area}

Markazi province is located in the central region of Iran and is surrounded by Isfehan, Lorestan, Hamedan, Qazvin, Alborz, Tehran, and Qom provinces. Markazi province is to the east of the intersection of the Alborz and Zagros mountain ranges with an area of $29.108 \mathrm{~km}^{2}$ (Figure 1). Due to its proximity to the target market and suitable geopolitical situation and climatic conditions, the province is considered the industrial hub of Iran, and many industries are located in the province. Proper working conditions over the past decades have led to the migration of many people, while, at the same time, due to the unregulated growth of industries, the province has fallen victim to environmental pollution immigrant workers (Statistical Center of Iran, 2016).

\section{Analytical framework}

The study presents a selected methodology for industrial sites and applies it to the specific case of the Markazi province area. A common-sense method is employed and integrated with the criteria extracted from legal frameworks and guidelines (Makhdoum, 2015). This study presents a GIS-based MCDM that will identify the most suitable sites for the development of industry in Markazi province using the ANP method. This process involves the use of spatial data and decision-maker preferences as well as combined data from both. It offers the flexibility of GIS to evaluate geographic data and the ability of MCDM to integrate geographical data for real-world assessment. Due to the importance of identifying suitable sites, this model offers a hybrid solution as a suitable option for integrated assessment and corrective decision-making when selecting areas for industrial purposes. The GIS-based MCDM framework is made up of six stages, including to (1) determine the main criteria and limitations according to the standards, (2) identify weighing of criteria and sub-criteria using ANP from experts, (3) prepare map layers, (4) normalize the criteria maps values, (5) overlay the data and create the land capability map, and (6) eliminate the constraints from the land capability map and classify the final map into sub-categories (Figure 2).

Grid-based criteria mapping was performed using ArcGIS 10.6.1 software with weight applied to each factor using Eq. (1).

$\operatorname{grid}_{\text {result(basiccriteria-limitations) }}=\sum_{\mathrm{i}=1}^{\mathrm{n}}\left(\operatorname{grid}_{\mathrm{i}} * \mathrm{~W}_{\mathrm{i}}\right)$

where $n$ is upper limit of the summation, $i$ index of the summation, and $W$ weight.

In order to evaluate the land suitability for industrial use in Markazi province, primary data were prepared from
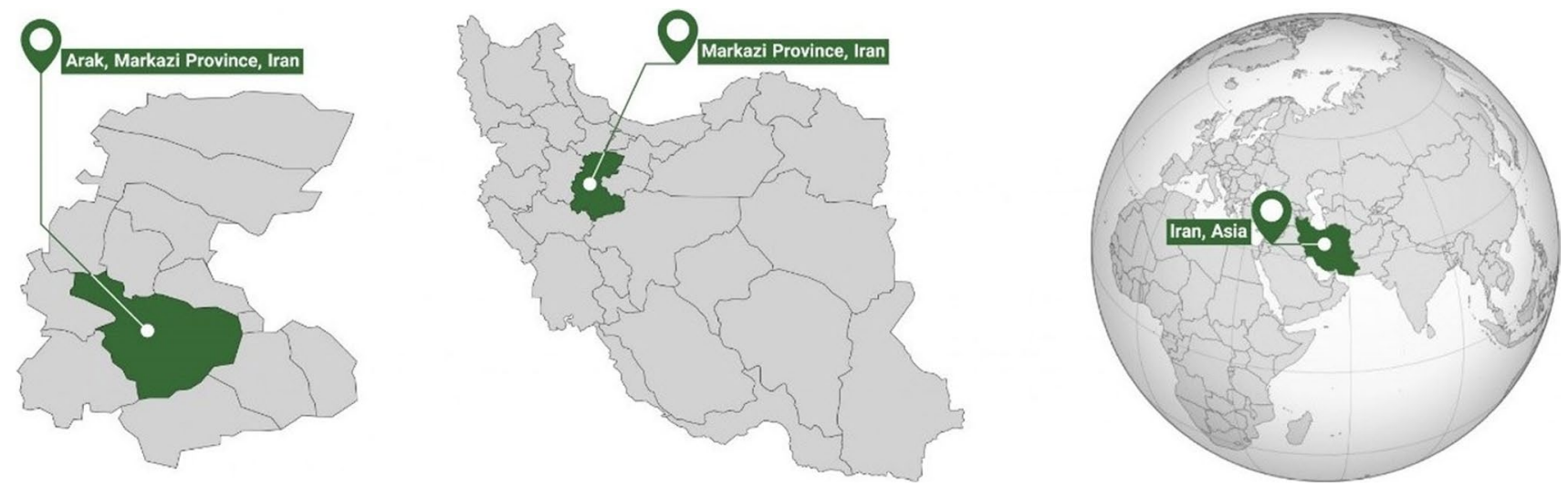

Figure. 1 Markazi province location in Iran 


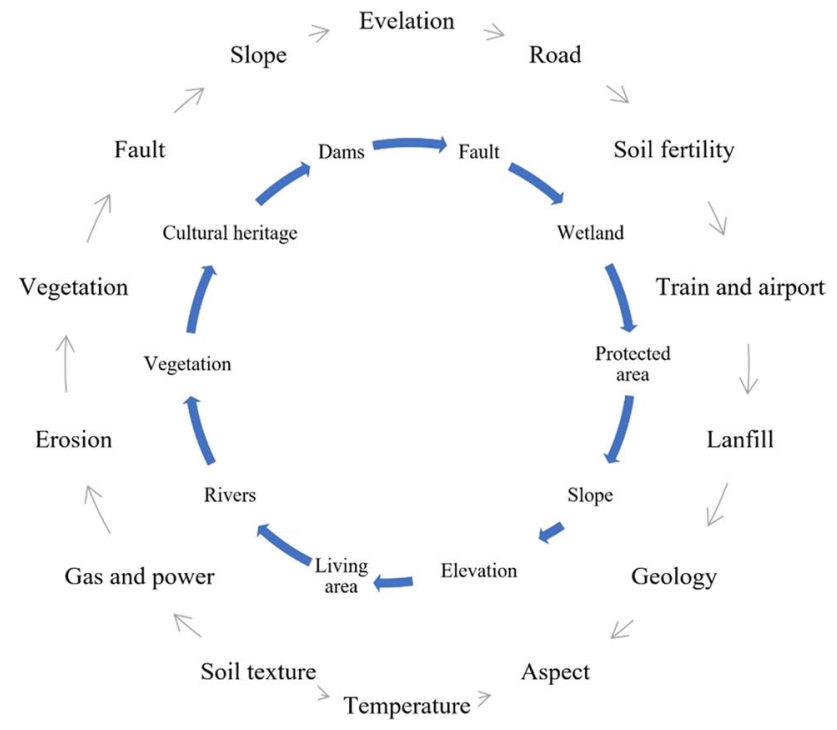

Figure. 2 Main parameter (i.e., external cycle) and limitations (i.e., internal cycle) involved in the industrial land capability assessment.

different sources. Table 1 shows the list of data along with their references.

After preparing the initial layers using ArcGIS software, the required processing is performed. First, the layers were cut by the political boundary of the Markazi province layer. Next, the coordinate system of all the layers became filed as the WGS_1984_UTM_Zone_39N system. After which the layers are applied according to the real-world data of the study area and the weight of each class. Afterward, using the GIS software algorithm, the area of each of the used layer classes is calculated and presented separately for each layer in the relevant tables. The primary and processed data were then overlaid to determine the industrial area. Note, the raster base method and raster data were used to place the resource layers, i.e., all primary data were allocated to raster layers with $30-\mathrm{m}$ resolution via assigned weight. The weights of the layers and the classes were obtained using the expert opinion using the ANP model.

\section{Criteria development}

In this paper, suitable site selection and zoning for the development of industrial parks are employed using an appropriate set of criteria via an MCDM process. All criteria were gathered through a literature review, expert opinion, local conditions at the provincial level, and by applying national Iranian standards (Makhdoum, 2015). The research used a snowball technique to identify the participating group of experts. Snowball sampling is a nonprobability sampling technique that samples selected members by contacting formerly sampled members who potentially could contribute to a specific study (Benaquisto, 2008; Voicu and Babonea, 2011). In the procedure of gathering the questionnaires, 32 experts were selected from the Arak University (i.e., 10 experts) and Markazi province's industries and mining organizations (i.e., 22 experts) in September 2020. It should be noted that a total of 64 questionnaires were administered among experts with only half of which were completed. To better clarify criteria development for the study, the definitions of a factor and constraint are defined. A factor is a criterion that enhances or detracts from the suitability of a specific alternative for the activity under consideration. It is therefore measured on a continuous scale. In this study, we consider these assessment factors which make up physical, economic, infrastructural, landform, and climatic criterions. A constraint serves to limit the alternatives under consideration. In many cases, as in this study, constraints are expressed in the form of a Boolean (logical) map, i.e., areas excluded from consideration are coded with a zero, while

Table 1 Raw data layer sources of the study

\begin{tabular}{lll}
\hline Raw & Layer & Reference \\
\hline 1 & Political divisions of the country, cities, and the central province & Iranian National Cartographic Center \\
2 & Digital elevation model (DEM) & DEM SRTM $^{\dagger}$ with 30 m raster resolution \\
3 & Slope, elevation, and aspect & Prepared from DEM in ArcGIS environment \\
4 & Soil texture and depth, soil structure, geology (parent rocks), and infrastruc- & Markazi province plan and budget organization \\
& ture (i.e., gas lines, power lines, roads, train station, and airport) & \\
5 & Vegetation density & Markazi province forest range and watershed \\
& & management organization \\
6 & Soil erosion and soil fertility & Markazi province agriculture organization, Jahad \\
7 & Landfill, wetlands, and protected areas & Department of Environment, Markazi province \\
8 & Historical and cultural heritage & Tourism organization of Markazi province \\
9 & Dams and hydrological networks & Regional water company of Markazi Province \\
10 & Weather and temperature & Markazi province meteorological organization
\end{tabular}

${ }^{\dagger} S R T M$ shuttle radar topography mission 
those open for consideration are coded with a one (Rikalovic et al., 2013). Moreover, in order to better explain the questionnaires to the experts and reduce the inconsistency rate as well as increase the validity of the weighted results, the questionnaires were completed face to face and in the place of activity of the experts. The final overlaid map was divided into five spatial categories, as follows: 1 . Exclusion zone, 2. Very low suitability, 3 . Low suitability, 4 . Moderately suitable, 5 . Highly suitable, and 6. Extremely suitable.

\section{Analytical network process}

Various studies have used ANP-based methods in land capability and zoning (Aragonés-Beltrán et al., 2010; Kuei-Lun et al., 2015; Zarei et al., 2016; Arsic et al., 2017; Yunna et al., 2018; Chao et al., 2020; Ghobadi et al., 2021). The ANP procedure is realized through four steps (Saaty, 2006; Panić and Lovren, 2014). First, the defining of the model and structuring of the problem are performed. The interpretation of the problem is done through a system similar to a network. The next step includes the comparison of the elements of decision pairs in each cluster and determination of the priority in regard to the control criterion (Malmir et al., 2016). Interdependence between the cluster criteria is also examined and compared using the Saaty standard scale (Seyedmohammadi et al., 2018). The super matrix is formed in the third step. In order to attain a global priority in the system with the inter-dependable influences, the local priority vectors are entered into the corresponding matrix columns. The result is a super matrix which is, in fact, a divided matrix where each segment represents the connection between the two clusters in the system. The synthesis of the criteria and alternative priorities is done in the last step as well as the selection of the best alternative. In order to perform global priority vectors, the obtained super matrix from the previous step, which is in this case also equal to the weighted super matrix, should be raised to the limiting powers, as in Eq. (2) (Yuksel and Dagdeviren, 2007).

$\lim _{k \rightarrow \infty} W^{k}$

where $W$ is weighted super matrix and $k$ element.

Raising the super matrix (i.e., in this case the weighted super matrix) to exponential powers produces the longterm relative influences of the elements towards each other (Saaty, 2006). In addition, if the super matrix has the effect of cyclicity, there may be two or $N$ limiting super matrices, as in Eq. (3).

$\lim _{k \rightarrow \infty} \frac{1}{N} \sum_{i=1}^{N} W_{i}^{k}$ where $W$ is weighted super matrix and $k$ element, $N$ number of super matrices, and $i$ index of summation.

Finally, the ANP methodology used for the collective evaluation, where values that form the estimates of the group for the compared elements of decision pairs are formed by the stakeholders in the group using the product sequence formula, Eq. (4).

$a_{i j}=\left(\prod_{p=1}^{s} a_{i j p}\right)^{\frac{1}{s}}$

where $a_{i j}$ is the priority vector acquired from the identical pairwise comparison indicating the significance of the elements in the $i^{\text {th }}$ cluster with respect to an element in the $j^{\text {th }}$ cluster, $s$ number of product sequences, and $p$ index of summation.

One of the important points in this research is that in order to improve the quality of study and, thus, make more accurate, the land capability assessment, i.e., in addition to weighing the main criteria, is weighing each main criterion's sub-criteria to best ascertain their importance.

\section{Results}

After distributing the questionnaires among the experts and weighing them by Super Decision 2.10 software, the weighted results were determined, according to which, due to the mountainous nature of the region, the slope parameter with a weight of 0.241 had the highest weight. In addition, the inconsistency rate that is necessary to increase the validity of the weighting, i.e., it is usually recommended to be less than 0.1 (Saaty and Ozdemir, 2005), is equated to 0.06055 which is considered acceptable.

Following the determining the weight between the criteria, another part of the weighing process breaks down which the weight of the classes of each criterion. At this stage, with the help of the ecological land capability potential assessment model (Makhdoum, 2015) of the industrial use and natural conditions of the study area, different classes of layers were determined, and experts were asked to assign weight to each class (Table 2). The importance of this, contrary to conventional methods, is that classes with higher utility will receive more weight, i.e., be more suitable. For example, in the past, distance from road classes up to $5 \mathrm{~km}$ and above $10 \mathrm{~km}$ has been of equal importance, while according to the results of this study, the weight of $0-5-\mathrm{km}$ class in Markazi province for industrial use is more than 5 times the weight of the more than $10-\mathrm{km}$ class. After determining the weight between the criteria and the criteria classes, and applying them to the existing layers (Figure 3), results from the restrictions base data (Table 3) and maps (Figure 4) are 


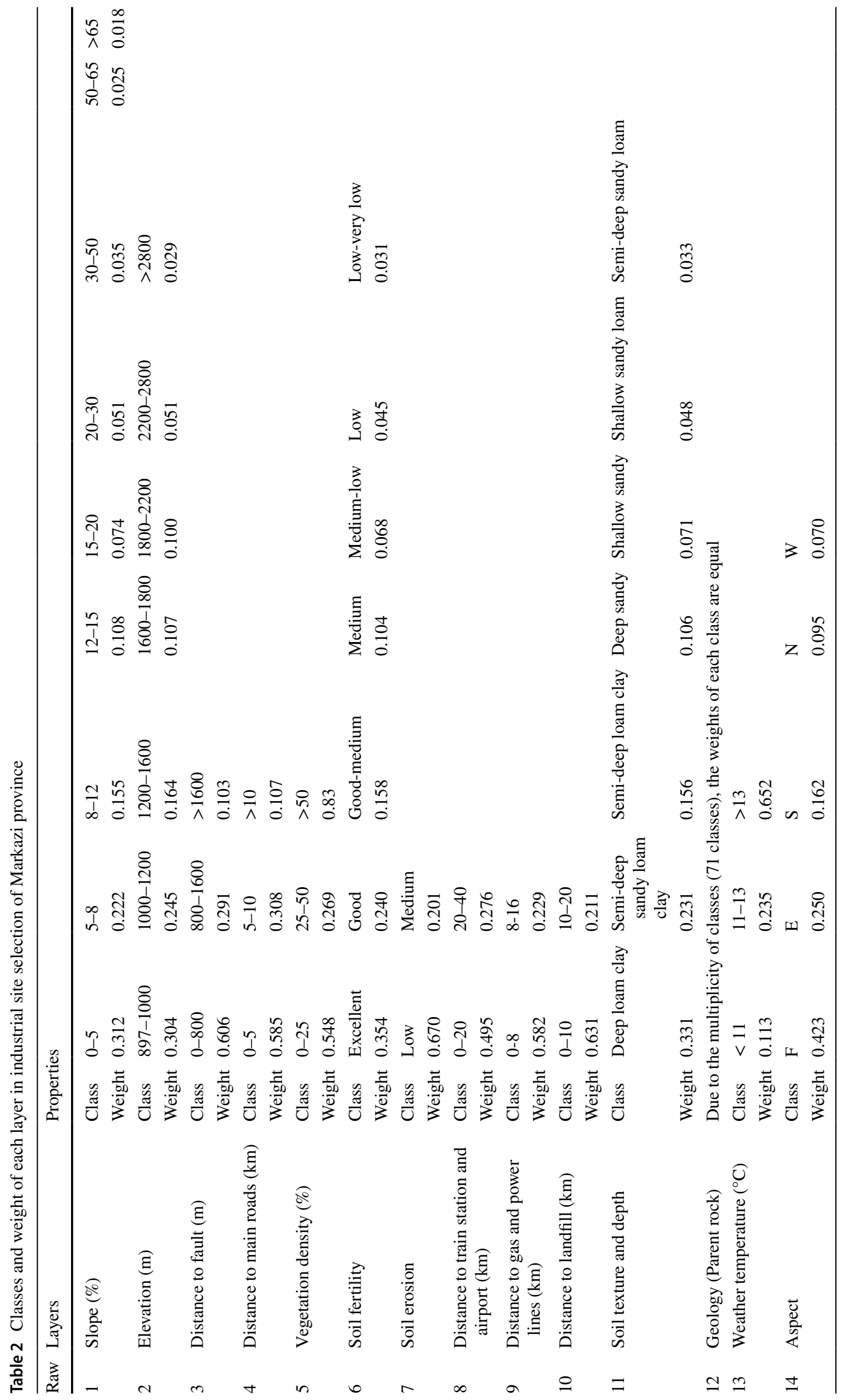




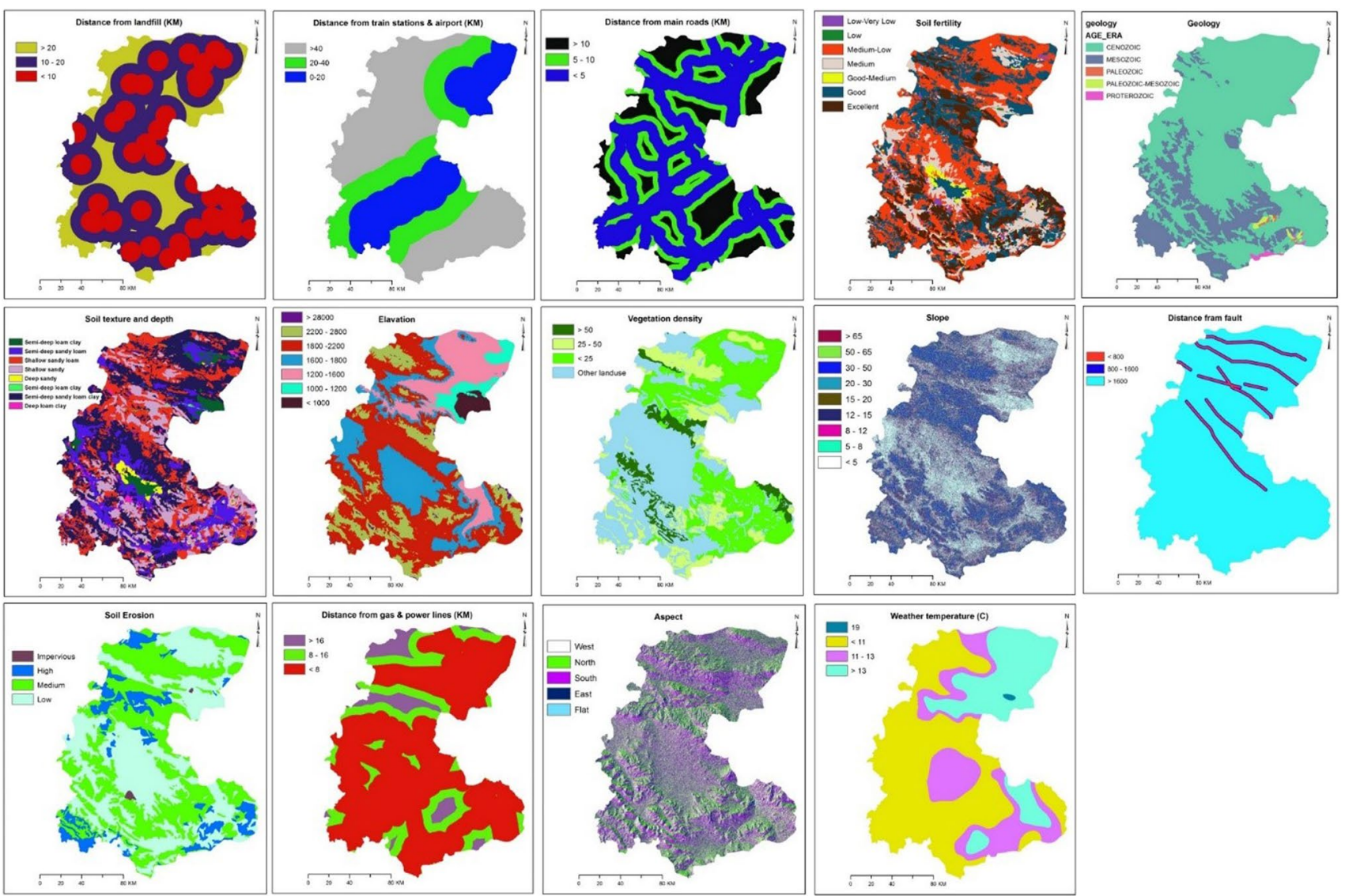

Figure 3. Classification map of each criterion. Note: All of the maps have a latitude from $33^{\circ} 0^{\prime} 0^{\prime \prime} \mathrm{N}$ to $36^{\circ} 0^{\prime} 0^{\prime \prime} \mathrm{N}$ and a longitude from $48^{\circ} 30^{\prime}$ $0^{\prime \prime} \mathrm{E}$ to $51^{\circ} 10^{\prime} 0^{\prime \prime} \mathrm{E}$.

created-since it is not possible to create development in these areas due to natural and legal limitations.

Finally, modeling was performed with all the standard maps with the output from suitable areas for industrial development in Markazi province (Figure 5). The results of the industrial land capability assessment model show that despite the fact that $60.14 \%$ of the area of Markazi province has no potential for industrial development, more than $25 \%$ of the province's area does (i.e., $14.27 \%$ is highly suitable and $11.32 \%$ is extremely suitable) (Table 4 ).

The areas with highly and extremely suitable potential delineate much of the center, west, and northeast of Markazi province as industrial development-friendly. Based on the results, among the 18 industrial parks in the Markazi

Table 3 Limitation imposed on industrial land use

\begin{tabular}{lll}
\hline Figure 4 label & Layer & Limitation \\
\hline A & Vegetation density (\%) (Makhdoum, 2015) & $>50$ \\
B & Distance from rivers (M) (Department of Environment, 2019) & $<650$ \\
C & Slope (\%) (Makhdoum, 2015) & $>15$ \\
D & Meyghan wetland buffer (M) (Department of Environment, 2019) & $<1500$ \\
E & Distance from protected area (M) (Makhdoum, 2015) & $<1000$ \\
F & Living areas (urban) (m) (recommended by the experts of the Markazi province plan and budget organization) & $<2500$ \\
$\mathrm{G}$ & Distance from dams (m) (recommended by the experts of the Markazi province plan and budget organization) & $<2000$ \\
$\mathrm{H}$ & Distance from historical and cultural heritage (m) (recommended by the experts of the Markazi province plan & $<1500$ \\
& and budget organization) & $<800$ \\
$\mathrm{I}$ & Distance from fault (m) (Tehran disaster mitigation and management organization, 2016) & $>2200$ \\
\hline
\end{tabular}



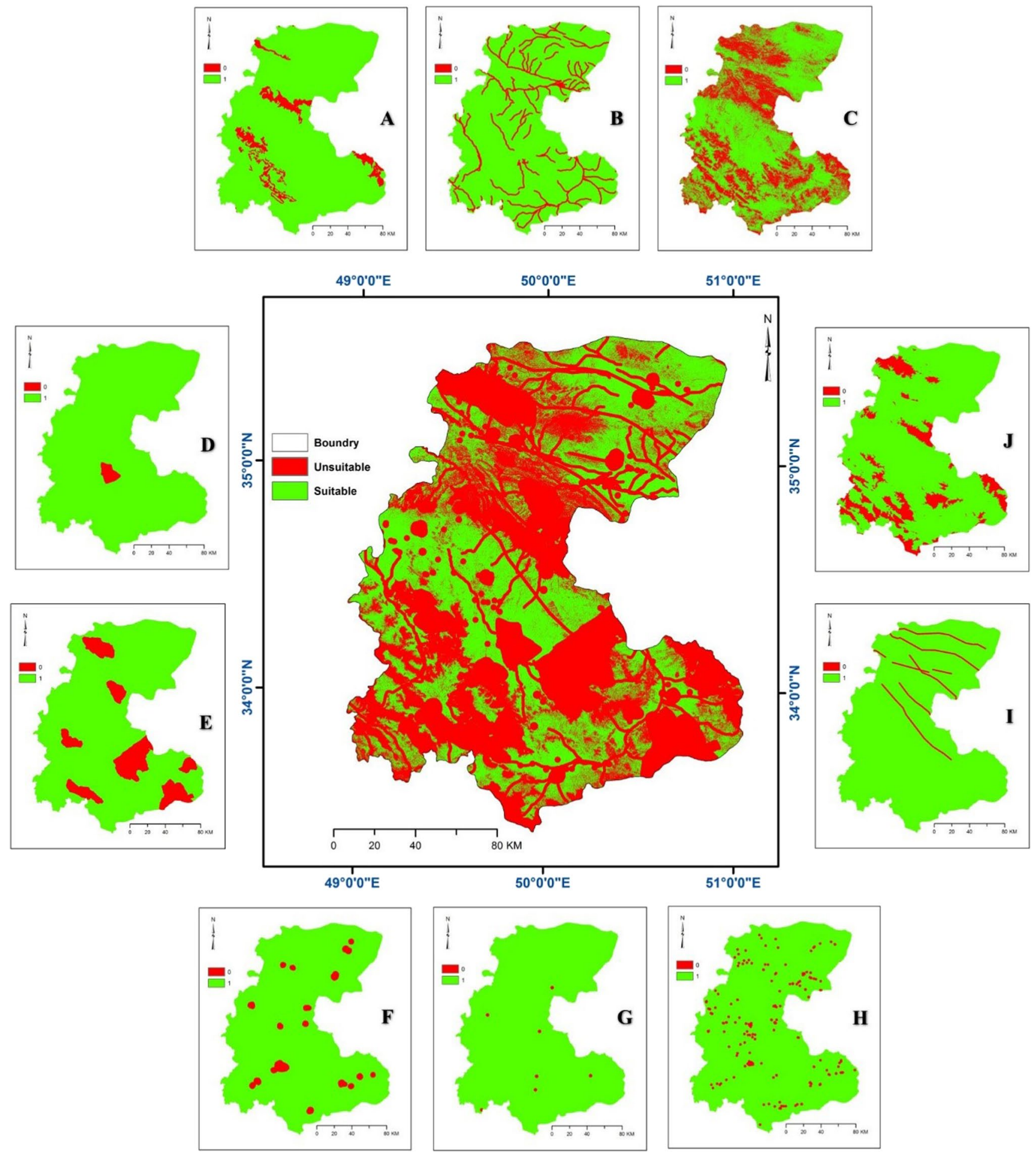

Figure 4. Map of restrictions on locating industrial land use in Markazi province $(0=$ area with industrial development limitations, $1=$ area without industrial development limitations). Note: Maps A

province, eight industrial parks are located in the exclusion zone which necessitates a high level of attention and care (Table 5). Any uncertainty in the findings, however, is dependent on the precision of current data and depth of the to $\mathrm{H}$ have a latitude from $33^{\circ} 0^{\prime} 0^{\prime \prime} \mathrm{N}$ to $36^{\circ} 0^{\prime} 0^{\prime \prime} \mathrm{N}$ and a longitude from $48^{\circ} 30^{\prime} 0^{\prime \prime} \mathrm{E}$ to $51^{\circ} 10^{\prime} 0^{\prime \prime} \mathrm{E}$.

analysis via the capability assessment model. To improve the results, it would be necessary to deepen the characteristics of the data, especially when creating maps that outline the terrain with a slope of less than 5\%. Environmental surveys 
Figure 5. Land potential for industrial development and current industrial park in Markazi province.

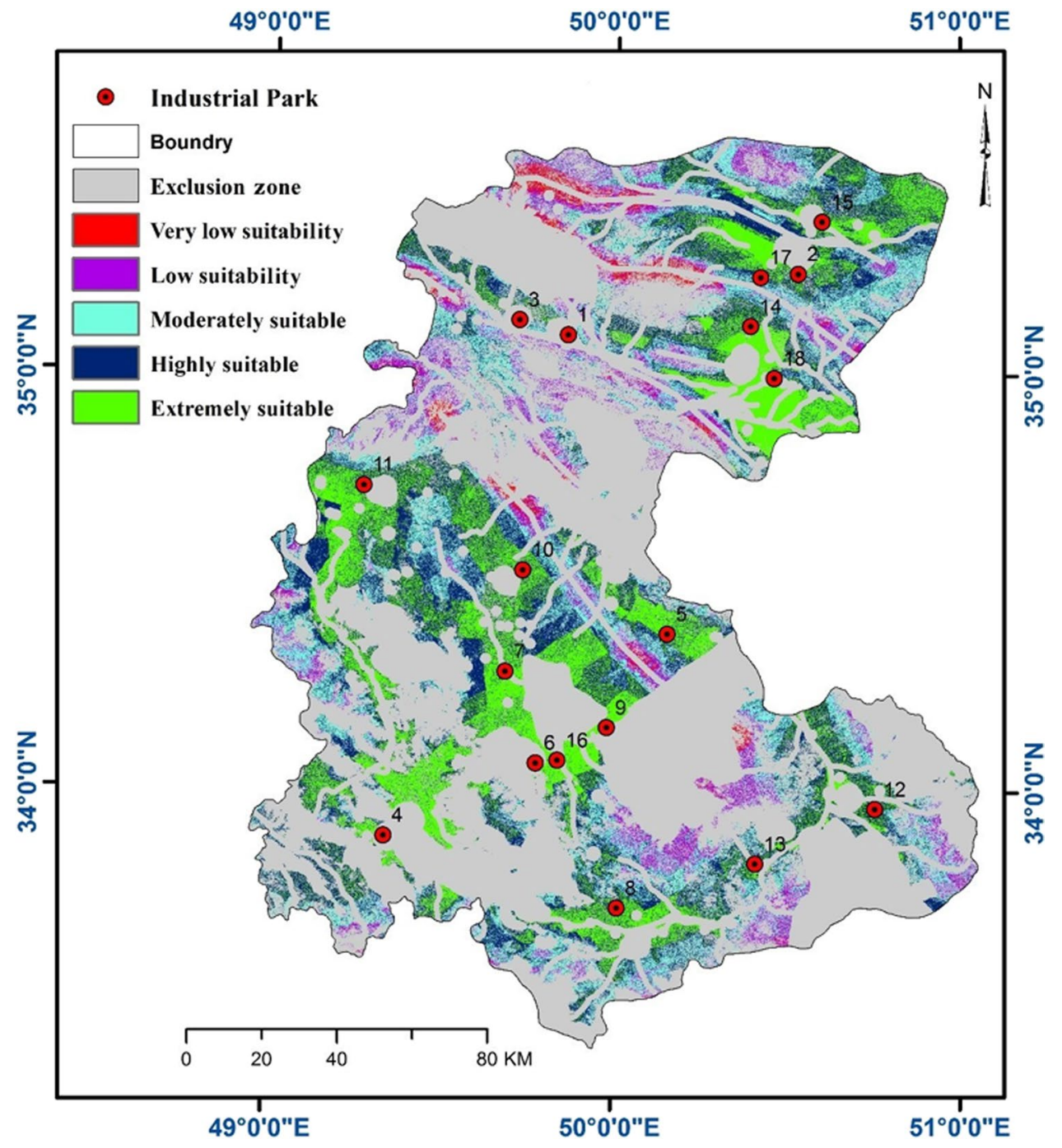

Table 4 Area of industrial development classification in Markazi province

\begin{tabular}{llcc}
\hline Raw & Land potential & Area $\left(\mathrm{km}^{2}\right)$ & Area $(\%)$ \\
\hline 1 & Exclusion zone & $17,506.3$ & 60.14 \\
2 & Very low suitability & 191.55 & 0.66 \\
3 & Low suitability & $1,230.18$ & 4.23 \\
4 & Moderately suitable & $2,732.00$ & 9.38 \\
5 & Highly suitable & $4,152.15$ & 14.27 \\
6 & Extremely suitable & $3,296.27$ & 11.32 \\
\hline
\end{tabular}

in conjunction with a cost-benefit analysis in the selected locations could also enhance proper construction criteria and relay a higher resolution of industrial site selection results.

Finally, in order to assess the sensitivity of the weighing system, a sensitivity analysis was conducted to examine the suitability of the assigned weights by the experts. The results of the sensitivity analysis are shown in Table 6 and illustrated in the Supplementary Information, Figure S1 and S2. Regarding the weight of the main parameters for the land evaluation of the industrial areas of Markazi province, it is confirmed that the results of the study, whether increased or decreased, does not exceedingly change the priority of the main parameters.

\section{Discussion}

This paper presents a land capability framework for evaluating industrial parks by using ANP. A complex MCDM problem is simplified by using the GIS-ANP methodology, which considers both quantitative and qualitative judgments to evaluate a set of criteria as well as interdependencies among the criteria. The customizable framework serves as a reference model providing logistics managers with a better understanding of industrial areas that are of key importance. It focuses on a best set of industrial parks for land evaluation 
Table 5 Current industrial park classification in Markazi province based on the land capability assessment

\begin{tabular}{lll}
\hline Raw & Industrial park & Classification \\
\hline 1 & Gharghabad & Exclusion zone \\
2 & Mamuniyeh & Highly suitable \\
3 & Nowbaran & Exclusion zone \\
4 & Astaneh & Exclusion zone \\
5 & Ashtian & Extremely suitable \\
6 & Arak & Exclusion zone \\
7 & Eybak Abad & Extremely suitable \\
8 & Khomein & Extremely suitable \\
9 & Kheyr Abad & Extremely suitable \\
10 & Farmahin & Extremely suitable \\
11 & Komijan & Extremely suitable \\
12 & Delijan & Highly suitable \\
13 & Mahalat & Exclusion zone \\
14 & Kaveh & Highly suitable \\
15 & Zavieh & Exclusion zone \\
16 & Haji Abad & Extremely suitable \\
17 & Zarandieh & Exclusion zone \\
18 & Saveh & Exclusion zone \\
\hline
\end{tabular}

by assessing the performance of industry inventory and distribution systems. For land capability of industrial areas, the correlated environmental, social, and economic elements constructed an evaluation indicator system. This was the first challenge in the site selection model. Current research combining GIS-based site selection in conjunction with an ANP algorithm to evaluate suitable sites (i.e., via land capability) proved to be very beneficial for industrial development purposes. The combined methods determined suitable areas for industries based on the selected criteria. In some circumstances, where decision-making is has critical, it is crucial to use a method that considers all aspects. The GIS-based and ANP applied approach can improve the performance of managers and planners for spatial assessment procedures by providing all dimensions based on a set of evaluation criteria. GIS-based MCDM is a fast and cost-effective method for industrial site selection purposes. There are diverse studies that verify the benefits of MCDM methods in the GIS environment for industrial site selection purposes (Ramaya and Devadas, 2019; Cunden et al., 2020; Saraswat et al., 2021, Sun et al., 2021; Caner and Aydin, 2021), especially in Iran, notably Reisi et al. (2011), Masoudi and Jokar (2015), Fataei et al. (2015), Amini (2015), Arabsheibani et al. (2016), Ahmadipari et al. (2018), Kishani Farahani (2018), Salari et al. (2019), and Moradi et al. (2020). The difference of this study with other research has been its comprehensiveness and integrity of information, in so that, it has made the effort to use the most effective data in the field. To this extent, the accuracy of the information utilized is more practical (i.e., accurate) than previous studies-since it weighted criteria and sub-criteria in the form of a network-resulting in all the pixels in the final map having their own weight and value.

After constructing the evaluation indicator system, the quantified weighing of the criteria followed by the ranking of the alternatives make up the most important stages in the site selection MCDM process. Based on the fact that the indicator system is a simplified 14 indicator and 10 limitation parameter framework, the importance of social and economic conditions played a key complimentary role in the final results. Moreover, since the sensitivity of environmental and local community conditions, in Markazi province, were linked in the GIS formulation, they acted as constraint factors weighing higher values to the slope, elevation, and distance from fault. Applying this model based on the GISANP analysis offers the best locations for industrial development by maximizing the strengths and opportunities and minimizing the weaknesses and threats. Overall synthesis of the previous facts suggests that the only possible and logical alternative for the management of industrial development is the development in the highly and extremely suitable areas which can offer a positive impact on regional development.

Post-development industrial site selection is a spatial problem in many developing countries, such as Iran. This type of industrial developmental sprawl usually occurs over a number of decades, requires considerable monitoring and reporting, and considers alternative areas as vital for industrial expansion and development. Spatial decision-based problems typically involve a large set of feasible alternative areas. In this paper, the problem of selecting appropriate industrial locations was resolved by applying a number of basic criteria for industrial sites. This process reduces the time required for decision-making, increases efficiency, and offers visually easy to understand output. The method optimizes the number of potential sites by labeling the highly and extremely suitable areas - aiding in the overall quality of site selection. The developed model allows decision-makers to decide in a short amount of time a number of alternatives for industrial sites province-wide and demonstrates clearly its utility as a decision support system. The complexity of such problems is reduced by efficient resolution and criteria optimization. Optimizing the number of criteria, standardizing criterion scores, and making suitability map for each criterion give us the opportunity to perceive each criterion separately and together through the final suitability map. Suitability maps as methods of visualizing problems much faster than complex datasets and tables. GIS-based MCDA represents a simple support tool for decision-makers. As such, stakeholders of the industrial areas in the Markazi province can prioritize their activities with specific environmental, social, economic, and technical constraints for best site selection practice. Moreover, the technique permits the 


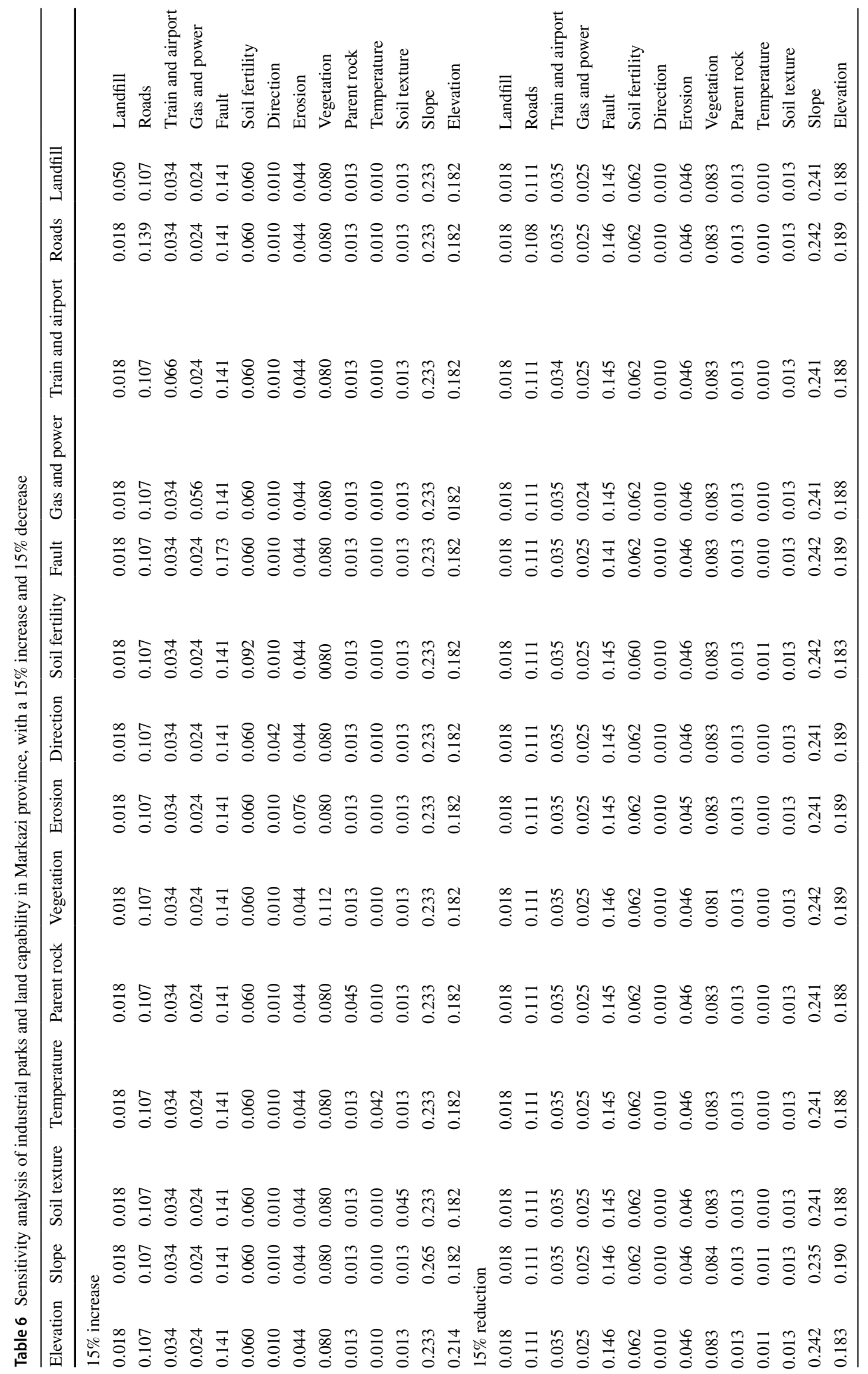


quick implementation of new scenarios. It should be noted that one of the weaknesses of the method presented is database robustness. This is important, since in many parts of Iran, due to the country's climatic and geomorphological makeup, land capability should be carried out, in practice, at the watershed level. However, due to political boundaries, it is only possible to assess the capability at the provincial level-with additional aid of layers produced nationally. A second weakness is the accuracy of the findings, i.e., regardless of how well the sensitivity analysis and spatial examination of the output are performed, validity may still need further interpretation. To do this, the use of combined methods, e.g., the landscape ecology approach or various remote sensing techniques, can be an effective way to increase the validity of the results. Finally, the proposed method generalizes an overall applicability to industrial land use and does not specify a distinction between different types of industrial needs. Future research could be industry-specific and focalize on industrial zoning specific to different operational requisites.

\section{Conclusion}

Land evaluation of industrial sites is an important factor in planning for regional development. One important technique used to maximize this process is land capability assessment. Industrial site selection can play an important part of the land use planning strategy specific to socioeconomic and ecological factors. Land capability assessment can involve the sophisticated process, with varying alternatives, of a multi-criteria technique. In this paper, Markazi province is characterized by its unique industrial infrastructure, resulting from its geographic, geopolitical, and climatic features. Through these considerations, the development of numerous human activities-province-wide-has underscored a demand to expand its industrial area. In this research, a method for optimal allocation of industrial parks based on the GIS-ANP technique is proposed. For this purpose, the maximum number of available layers is used, i.e., 14 main criteria and 10 layers of constraints, to best portray industrial site selection. The results of the study showed that $44 \%$ of the province's industrial parks are located in unsuitable areas and about $25 \%$ has acceptable potential for the development of industrial units. This issue can be considered from several dimensions; first, the need to pay close attention to the existing industrial centers and properly organize them, given that a relatively large number are located in inappropriate parts of the province. Second, the development of other units in the future should be done as carefully as possible because the potential areas are mostly occupied and relatively sparse. Taking into account the dissatisfaction of the indigenous community's attitude towards industrial pollution, i.e., especially air pollution, climatic events, and water shortages, these issues will force policymakers to work on organizing and centralizing existing units and perhaps re-think of strategies to reduce the number of units in the long term (Kishani Farahani, 2018). To this effect, the study provides an accurate understanding that supports sustainable industrial land use policy specific to Markazi province. Based on this application, the proposed model represents a suitable tool for decision-making by providing an operational framework for the sustainable development for other region's industrial parks. The model proposed consists of different phases that make it flexible, in the sense that its network structure and rules allow minor adjustments, for the purpose of applying it to similar problems in the management of the environment in other arid and semi-arid areas. Further research should investigate the results obtained by the GIS-based ANP methodology and optimize it for future regional development.

Supplementary Information The online version contains supplementary material available at https://doi.org/10.1007/s12518-021-00415-x.

Acknowledgements The authors are extremely grateful to the Iranian National Cartographic Center, Markazi province planning and budget organization, forest range and watershed management organization, agriculture organization at Jahad, tourism organization, regional water company, meteorological organization, and Department of Environment.

Author contribution A.H.A., A.A., M.H., and S.Z. collected, analyzed, and interpreted the data and wrote the manuscript. G.T.C. edited and revised readability of the manuscript and amended the methodology. All authors read and approved the final manuscript.

Funding This research was funded by the Markazi province Office of Planning and Budget Organization, Grant No. 688030.

Markazi province Office of Planning and Budget Organization,Grant No. 688030,Amir Hedayati Aghmashhadi

Data Availability The data are available from the corresponding author on reasonable request.

Code availability Not applicable.

\section{Declarations}

Ethics approval The Ethical Committee has proved that this study complies with the ethics of scientific research described in the Ethical Principles of the Declaration of Helsinki and other applicable ethical principles and legislation.

Consent to participate Not applicable.

Consent for publication Not applicable.

Conflict of interest The authors declare no competing interests.

Open Access This article is licensed under a Creative Commons Attribution 4.0 International License, which permits use, sharing, adaptation, distribution and reproduction in any medium or format, as long 
as you give appropriate credit to the original author(s) and the source, provide a link to the Creative Commons licence, and indicate if changes were made. The images or other third party material in this article are included in the article's Creative Commons licence, unless indicated otherwise in a credit line to the material. If material is not included in the article's Creative Commons licence and your intended use is not permitted by statutory regulation or exceeds the permitted use, you will need to obtain permission directly from the copyright holder. To view a copy of this licence, visit http://creativecommons.org/licenses/by/4.0/.

\section{References}

Ahamdipari M, Hoveidi H, Jafari HR, Pazoki M (2018) An integrated environmental management approach to industrial site selection by genetic algorithm and fuzzy analytic hierarchy process in geographical information system. Global J Environ Sci Manage 4(3):339-350. https://doi.org/10.22034/gjesm.2018.03.007

Aljohani K, Thompson RG (2020) A multi-criteria spatial evaluation framework to optimise the siting of freight consolidation facilities in inner-city areas. Transp Res Part A 138(2020):51-69

Al-Mulali U, Weng-Wai C, Sheau-Ting L, Mohammed AH (2015) Investigating the environmental Kuznets curve (EKC) hypothesis by utilizing the ecological footprint as an indicator of environmental degradation. Ecol Indic 48:315-323

Amini A (2015) a multi-criteria group decision making approach for rural industrial site selection using fuzzy TOPSIS in Central Iran. Social and Economic Geography 1(1):44-54. https://doi.org/10. 12691/seg-1-1-7

Arabsheibani R, Sadat YK, Abedini A (2016) Land suitability assessment for locating industrial parks: a hybrid multi criteria decisionmaking approach using geographical information system. Geogr Res 54(4):446-460

Aragonés-Beltrán P, Chaparro-González F, Pastor-Ferrando JP, Rodríguez-Pozo F (2010) An ANP-based approach for the selection of photovoltaic solar power plant investment projects. Renewable and Sustainable Energy Reviews 14(1):249-264

Arsic S, Nikolic D, Zivkovic Z (2017) Hybrid SWOT - ANP - FANP model for prioritization strategies of sustainable development of ecotourism in National Park Djerdap Serbia. Forest Policy and Economics 80:11-26

Cao W, Geng S, Zou J, Wang Y, Guo Y, Zhu Y, Dou J (2020) Post relocation of industrial sites for decades: ascertain sources and human risk assessment of soil polycyclic aromatic hydrocarbons. Ecotoxicology and Environmental Safety 198:110646

Caner HI, Aydin CC (2021) Shipyard site selection by raster calculation method and AHP in GIS environment İskenderun Turkey. Marine Policy 127:104439

Chao L, Yanbing J, Ernesto DRSG, Peiwu D, Aihua W (2020) The waste-to-energy incineration plant site selection based on hesitant fuzzy linguistic Best-Worst method ANP and double parameters TOPSIS approach: a case study in China. Energy 211:118564

Chauhan A, Singh A (2016) A hybrid multi-criteria decision-making method approach for selecting a sustainable location of healthcare waste disposal facility. J Cle Pro. 139:1001-1010

Cunden TSM, Dooraga J, Lollachund MR, Rughooputh SDDV (2020) Multi-level constraints wind farms siting for a complex terrain in a tropical region using MCDM approach coupled with GIS. Energy 211:118533

Iran's Department of Environment. 2019. Rules and regulations for the establishment of production, industrial and mining units. Office of Environmental Assessment, Deputy of Human Environment, Iran's Department of Environment.
Diaz H, Soares CG (2020) An integrated GIS approach for site selection of floating offshore wind farms in the Atlantic continental European coastline. Renewable and Sustainable Energy Reviews 134:110328

Fataei, E., Aalipour, M., Farhadi, H., Mohammadian, A. 2015. Industrial state site selection using MCDM method and GIS in Germi, Ardabil, Iran. Journal of Industrial and Intelligent Information Vol. 3, No. 4, December 2015. https://doi.org/10.12720/jiii.3.4.324-329.

Fernández I, Ruiz M (2009) Descriptive model and evaluation system to locate sustainable industrial areas. J Clean Prod 17:87-100

Ghobadi M, Nasri M, Ahmadipari M (2021) Land suitability assessment (LSA) for aquaculture site selection via an integrated GISDANP multi-criteria method; a case study of Lorestan province Iran. Aquaculture 530:735776

Giap DH, Yi Y, Yakupitiyage A (2005) GIS for land evaluation for shrimp farming in Haiphong of Vietnam. Ocean Coast Manag 48:51-63

Benaquisto, L, M. 2008. The SAGE encyclopedia of qualitative research methods. A SAGE reference publication.

Hadipour A, Vafaie F, Hadipour V (2014) Land suitability evaluation for brackish water aquaculture development in coastal area of Hormozgan. Iran. Aquaculture International 23(1):329-343

Hasala D, Supak S, Rivers L (2020) Green infrastructure site selection in the Walnut Creek wetland community: a case study from southeast Raleigh North Carolina. Landscape and Urban Planning 196:103743

Izadikhah M, Saen RF (2016) A new preference voting method for sustainable location planning using geographic information system and data envelopment analysis. J Cle Pro 137:1347-1367

KishaniFarahani M (2018) Environmental land use planning for industrial site selection using GIS and AHP case of Arak City Iran. Journal of Environmental Science and Technology. https:// doi.org/10.22034/JEST.2018.10727.1930

Khamis A, Khatib T, Yosliza NAHM, Azmi AN (2020) Optimal selection of renewable energy installation site in remote areas using segmentation and regional technique: a case study of Sarawak Malaysia. Sustainable Energy Technologies and Assessments 42:100858

Kuei-Lun C, Sen-Kuei L, Tzeng-Wei T, Chi-Yi L (2015) An ANP based TOPSIS approach for Taiwanese service apartment location selection. Asia Pacific Management Review 20(2):49-55

Li Y, Wang Y, Gao X, Xie T, Hai R, Zhang X (2017) Multi-criteria evaluation method for site selection of industrial wastewater discharge in coastal regions. J Clean Prod. https://doi.org/10. 1016/j.jclepro.2017.05.030

Makhdoum M (2015) Fundamental of land use planning, Fifteenth. University of Tehran Press, Tehran

Malczewski J (2004) GIS-based land-use suitability analysis: a critical overview. Progress in Planning 62(1):3-65

Malmir, M., Kheirkhah Zarkesh, M., Monavari, S, M. 2016. Analysis of land suitability for urban development in Ahwaz County in southwestern Iran using fuzzy logic and analytic network process (ANP). Environmental Monitoring and Assessment 188(8).

Masoudi M, Jokar P (2015) Land-use planning using a quantitative model and geographic information system (GIS) in Shiraz Township Iran. Ecopersia 3(2):959-974

Meaden GJ, Aguilar-Manjarrez J (eds) (2013) Advances in geographic information systems and remote sensing for fisheries and aquaculture. Summary version. Food and Agriculture Organization of the United Nations, Rome, Italy

Mondini G (2016) Integrated assessment for the management of new social challenges. Valori e Valutazioni 17:15-18

Mousavi SH, Danehkar A, Shokri MR, Poorbagher H, Azhdari D (2015) Site selection for artificial reefs using a new combine multi-criteria decision-making (MCDM) tools for coral reefs in the Kish Island-Persian Gulf. Ocean Coast Manag 111:92-102 
Moradi S, Yousefi H, Noorollahi Y, Rosso D (2020) Multi-criteria decision support system for wind farm site selection and sensitivity analysis: case study of Alborz Province Iran. Energy Strategy Reviews 29:100478

Munda G (2004) Social multi-criteria evaluation: methodological foundations and operational consequences. Eur J Oper Res 158(3):662-667

Khavarian-Garmsir AR, Rezaei MR (2015) Selection of appropriate locations for industrial areas using GIS-fuzzy methods A case study of Yazd Township Iran. Journal of Settlements and Spatial Planning 6(1):19-25

Ramaya, S., Devadas, V. 2019. Integration of GIS, AHP and TOPSIS in evaluating suitable locations for industrial development: a case of Tehri Garhwal district, Uttarakhand, India. Journal of Cleaner Production, Volume 238, 20 November 2019, 117872.

Reisi M, Aye L, Soffianian A (2011) Industrial site selection by GIS in Isfahan Iran. June 2011 International Conference on Geoinformatics. https://doi.org/10.1109/GeoInformatics.2011.5981171

Rikalovic A, Cosic I, Labati RD (2017) A comprehensive method for industrial site selection: the macro-location analysis. IEEE Systems Journal. https://doi.org/10.1109/JSYST.2015.2444471

Rikalovic A, Cosic I, Lazarevic D (2014) GIS based multi-criteria analysis for industrial site selection 24th DAAAM International Symposium on Intelligent Manufacturing and Automation 2013. Procedia Engineering 69:1054-1063

Ross LG, Mendoza QMEA, Beveridge MCM (2013) The application of geographical information systems to site selection for coastal aquaculture: an example based on salmonid cage culture. Aquaculture 112:165-178

Saaty TL (2006) Fundamentals of decision making and priority theory with the analytic hierarchy process. RWS Publications, Pittsburgh

Saaty, T. L., Ozdemir, M. 2005. The Encyclicon. RWS Publications, 4922 Ellsworth Avenue, Pittsburgh.

Salari M, Shariat SM, Rahimi R, Dashti S (2019) Land capability assessment in order to establish usage of industrial town using multi-criteria decision making and AHP (case study: Qeshm Island). Quarterly of Geography (Regional Planning) 8(3):303-315

Saraswat SK, Digalwar AK, Yadav SS, Kumar G (2021) MCDM and GIS based modelling technique for assessment of solar and wind farm locations in India. Renewable Energy 169:865-884

Seyedmohammadi J, Sarmadian F, Jafarzadeh AA, McDowell RW (2019) Integration of ANP and Fuzzy set techniques for land suitability assessment based on remote sensing and GIS for irrigated maize cultivation. Archives of Agronomy and Soil Science 65(8):1063-1079. https://doi.org/10.1080/03650340.2018. 1549363

Statistical Center of Iran. 2016. Iran's 2016 National Population and Housing Census.

Sun L, Jiang Y, Guo Q, Ji L, Xie Y, Qiao Q, Huang G, Xiao K (2021) A GIS-based multi-criteria decision-making method for the potential assessment and suitable sites selection of PV and CSP plants. Resources Conservation and Recycling 168:105306

Tehran Disaster Mitigation and Management Organization. 2016. Criteria for building construction in fault zones of Tehran, Tehran, Iran.

Teniwut WA, Marimin M, Djatna T (2019) GIS-based multi-criteria decision-making model for site selection of Seaweed Farming Information Centre: a lesson from small islands Indonesia. Decis Sci Lett 8(2):137-150

Villacreses G, Gaona G, Martínez-Gómez J, Jijón DJ (2017) Wind farms suitability location using geographical information system (GIS), based on multi-criteria decision making (MCDM) methods: the case of continental Ecuador. Renew Energy 109:275-286

Voicu M, Babonea A (2011) Using the snowball method in marketing research on hidden populations. Chall Knowl Soc 1:1341-1351

Yuksel I, Dagdeviren M (2007) Using the analytic network process (ANP) in a SWOT analysis - a case study for a textile firm. Inf Sci 177:3364-3382

Yunna W, Buyuan Z, Chuanbo X, Lingwenying L (2018) Site selection decision framework using fuzzy ANP-VIKOR for large commercial rooftop PV system based on sustainability perspective. Sustainable Cities and Society 40:454-470

Zarei M, Fatemi MR, Mortazavi MS, Pouebrahim S, Ghoddousi J (2016) Selection of the optimal tourism site using the ANP and fuzzy TOPSIS in the framework of Integrated Coastal Zone Management: a case of Qeshm Island. Ocean \& Coastal Management 130:179-187

Zhang J, Xu C, Song Z, Huang YWu, Yunna (2019) Decision framework for ocean thermal energy plant site selection from a sustainability perspective: the case of China. Journal of Cleaner Production 225:771e784

Publisher's note Springer Nature remains neutral with regard to jurisdictional claims in published maps and institutional affiliations. 